\title{
PENGARUH PERUBAHAN TUTUPAN HUTAN DAN LAHAN TERHADAP PRODUK DOMESTIK REGIONAL BRUTO (PDRB) DI SEKTOR PERTANIAN, KEHUTANAN DAN INDUSTRI :STUDI DI PROVINSI LAMPUNG
}

\author{
(Forest Cover and Land Use Changes Effect Toward Regional Gross Domestic Product \\ (RGDP) in Agricultural, Forestry, and Industrial Sektor : Case Study in Lampung) \\ Ummi Dienelly, Samsul Bakri, dan Trio Santoso \\ Jurusan Kehutanan Fakultas Pertanian Universitas Lampung \\ Jl. Soemantri Brojonegoro No. 01 Bandar Lampung \\ E-mail : ummi.dienelly@gmail.com
}

\begin{abstract}
ABSTRAK
Pertumbuhan ekonomi nasional merupakan agregat dari pertumbuhan ekonomi daerah. Pertumbuhan ekonomi baik nasional maupun daerah berkaitan erat dengan kinerja produksi barang dan jasa, yang diukur dengan besaran dalam Produk Domestik Bruto (PDB) untuk nasional dan Produk Domestik Regional Bruto (PDRB) untuk daerah. Kinerja pertumbuhan ekonomi Provinsi Lampung yang cukup tinggi di sisi lain harus dibayar dengan konversi lahan. Penelitian ini bertujuan untuk menentukan dinamika perubahan tutupan lahan dan hutan serta dampaknya terhadap pendapatan di sektor pertanian, kehutanan dan industri. Data yang dikumpulkan meliputi data citra Provinsi Lampung, PDRB sektor pertanian, PDRB sektor kehutanan, PDRB sektor industri serta data kepadatan penduduk. Hasil penelitian menunjukkan bahwa ada hubungan yang berarti antara perubahan tutupan hutan rakyat $11.055(\mathrm{p}=0.062)$, sawah $7.982(\mathrm{p}=0.082)$, serta kepadatan penduduk -8.676 $(\mathrm{p}=0.000)$ terhadap PDRB di sektor pertanian. PDRB di sektor kehutanan dipengaruhi secara nyata oleh tutupan hutan negara 1.160 $(\mathrm{p}=0.00)$ dan areal lain $-0.803(\mathrm{p}=0.061)$. PDRB di sektor industri dipengaruhi secara nyata oleh tutupan hutan rakyat $-7.434(\mathrm{p}=0.077)$, dan perkebunan $5.471(\mathrm{p}=0.00)$.
\end{abstract}

Kata Kunci : PDRB sektor pertanian, PDRB sektor industri, PDRB sektor kehutanan

\section{ABSTRACT}

National economic growth is an aggregate of regional economic growth. Economic growth in both national and local level is closely related to the performance of the productions of goods and services, which measured by massive increase in the amount of the Gross Domestic Product (GDP) and Regional Gross Domestic Product (RGDP) for the region. Lampung province's economic growth performance is high enough but on the other hand had to be paid by land conversion. This study aims to determine the dynamic of changes in land cover and forest and its impact on agriculture, forestry and industrial earnings. Data collected consist of satelitte image of lampung province RGDP in agricultural sector, RGDP in foresty sector, RGDP in industrial sector and population density data. The result showed that there was a significant relationship beetwen changes in private forest cover by $11.055(p=0.062)$, rice field by $7.982(p=0.082)$, and population density by $-8.676(p=0.000)$ to the RGDP in agricultural sector. RGDP in the forestry sector is affected significantly by the national forest cover by $1.160(p=0.00)$ and other 
land use by $-0.803(p=0.061) . R G D P$ in the industrial sector is influenced significantly by private forest $-7.434(p=0.077)$, and plantation by $5.471(p=0.00)$.

Keyword : $R G D B$ agriculture sector, $R G D B$ forestry sector, $R G D B$ industri sector

\section{PENDAHULUAN}

Pembangunan perekonomian daerah melibatkan beberapa sektor maupun pihak yang berkepentingan. Muara dari pembangunan ekonomi daerah ini secara umum dapat memberikan kontribusi pada pertumbuhan ekonomi nasional. Adapun pertumbuhan ekonomi nasional merupakan agregat dari pertumbuhan ekonomi daerah. Pertumbuhan ekonomi baik nasional maupun daerah berkaitan erat dengan kinerja produksi barang dan jasa, yang diukur dengan besaran dalam Produk Domestik Bruto (PDB) untuk nasional ataupun Produk Domestik Regional Bruto (PDRB) untuk daerah. PDRB menggambarkan kemampuan daerah dalam mengelola sumberdaya pembangunan yang dimilikinya dalam kurun waktu tertentu untuk menghasilkan barang dan jasa (BPS, 2010-2014). Oleh karena itu besaran PDRB setiap daerah bervariasi sesuai dengan potensi yang dimiliki dan faktor produksi masing-masing daerah. Menurut Bappeda Provinsi Lampung (2013) laju pertumbuhan PDRB Provinsi Lampung pada tahun 2013 mengalami pertumbuhan rata-rata sebesar 5,97\%, angka tersebut lebih tinggi dibandingkan dengan rata-rata pertumbuhan ekonomi nasional yang hanya mencapai 5.78\%.

Kinerja pertumbuhan ekonomi Provinsi Lampung yang cukup tinggi tersebut di sisi lain harus dibayar dengan konversi lahan. Semakin tinggi kebutuhan lahan untuk pemukiman, sarana pelayanan serta industri akan menurunkan struktur penggunaan lahan pada batasan tertentu (Rohmadiani, 2011). Kegiatan konversi lahan menyebabkan pengrusakan habitat, fragmentasi, pergantian spesies yang sensitif terhadap spesies migrasi, dan degradasi habitat aqutik (Surni, 2015). Kerusakan tersebut sangat berpengaruh terhadap kinerja di sektor kehutanan, sektor pertanian dan sektor industri.

Berdasarkan permasalahan diatas maka perlu dilakukan penelitian mengenai pengaruh dari perubahan tutupan lahan di Provinsi Lampung terhadap kinerja di sektor kehutanan, pertanian dan industri. Hasil penelitian ini diharapkan dapat menjadi acuan maupun sebagai bahan masukan kepada pemerintah untuk membuat kebijakan mengenai perubahan tata ruang yang ada di Provinsi Lampung dan dampak yang diakibatkan oleh perubahan penutupan hutan dan lahan.

\section{METODE PENELITIAN}

Penelitian ini dilaksanakan Laboratorium Inventarisasi dan Pemetaan Hutan Jurusan Kehutanan Fakultas Pertanian Universitas Lampung. Penelitian dilakukan pada bulan SeptemberNovember 2015. Alat yang digunakan pada penelitian ini meliputi perangkat keras (laptop) dan perangkat lunak(Software), serta alat tulis. Objek dalam penelitian ini adalah citra satelit dengan perekaman peta luas tutupan kawasan hutan dan lahan tahun 2002, 2009 dan 2014. Data yang diambil dalam penelitian ini adalah data primer dan data sekunder. Data primer merupakan data yang diambil secara langsung dari sumber-sumber data. Data primer dari penelitian ini adalah berupa data cek lapang mengenai tutupan lahan. Data sekunder yaitu data yang didapatkan dari dinas maupun instansi pemerintahan berupa data PDRB di sektor pertanian, PDRB di sektor kehutanan, PDRB di sektor industri, data kepadatan penduduk serta citra landsat tutupan hutan 
path 123 row 063, path 123 row 064, path 124 row 063, path 124 row 064. Teknik analisis data yang digunakan adalah analisis model linier berganda. Analisis regresi berganda adalah hubungan secara linier antara dua atau lebih variabel independen $(\mathrm{X})$ dengan variabel dependen (Y). Teknik ini disebut linier karena setiap estimasi atas nilai yang diharapkan mengalami peningkatan atau penurunan mengikuti garis lurus. Pengukuran pengaruh variabel ini melibatkan lebih dari satu variabel bebas $(\mathrm{X} 1, \mathrm{X} 2, \mathrm{X} 3, . ., \mathrm{Xn})$ yang mempengaruhi variabel tetap (Y). Adapun model linier berganda yang digunakan adalah sebagai berikut:

\section{A. PDRB Sektor Pertanian}

$$
[\mathrm{Y}]_{1}=\beta_{0}+\beta_{1}[\mathrm{HN}]_{\mathrm{it}}+\beta_{2}[\mathrm{HR}]_{\mathrm{it}}+\beta_{3}[\mathrm{LTEB}]_{\mathrm{it}}+\beta_{4}[\mathrm{SWH}]_{\mathrm{it}}+\beta_{5}[\mathrm{KPD}]_{\mathrm{it}}+\mathrm{B}_{6}[\mathrm{AL}]_{\mathrm{it}}+e_{i}
$$

\section{Hipotesis}

$\mathrm{H}_{0}: \beta_{1}=\beta_{2}=\beta_{3}=\beta_{4}=\beta_{5}=\beta_{6}=0$

$\mathrm{H}_{1}: \beta_{1} \neq \beta_{2} \neq \beta_{3} \neq \beta_{4} \neq \beta_{5} \neq \beta_{6} \neq 0$

Keterangan:

$[\mathrm{Y}]_{1}=$ PDRB Sektor Pertanian (juta rupiah/ kabupaten, kota)

$[\mathrm{HN}]_{\mathrm{it}} \quad=$ Hutan Negara (ha)

$[\mathrm{HR}]_{\mathrm{it}} \quad=$ Hutan Rakyat (ha)

$[\mathrm{LTEB}]_{\mathrm{it}} \quad=$ Lahan Terbangun (ha)

$[\mathrm{SWH}]_{\mathrm{it}} \quad=$ Sawah (ha)

$[\mathrm{KPD}]_{\mathrm{it}} \quad=$ Kepadatan Penduduk $\left(\mathrm{jiwa} / \mathrm{km}^{2}\right)$

$[\mathrm{AL}]_{\mathrm{it}} \quad=$ Areal Lain (ha)

$e_{i} \quad=$ error model

$\beta_{0}, \beta_{1}, \ldots \beta_{6} \quad=$ Parameter Model

\section{B. PDRB Sektor Kehutanan}

$[\mathrm{Y}]_{2}=\alpha_{0}+\alpha_{1}[\mathrm{HN}]_{\mathrm{it}}+\alpha_{2}[\mathrm{HR}]_{\mathrm{it}}+\alpha_{3}[\mathrm{PTN}]_{\mathrm{it}}+\alpha_{4}[\mathrm{SWH}]_{\mathrm{it}}+\alpha_{5}[\mathrm{LTEB}]_{\mathrm{it}}+\alpha_{6}[\mathrm{KPD}]_{\mathrm{it}}+\alpha_{7}[\mathrm{AL}]_{\mathrm{it}}+e_{i}$

\section{Hipotesis}

$\mathrm{H}_{0}: \alpha_{1}=\alpha_{2}=\alpha_{3}=\alpha_{4}=\alpha_{5}=\alpha_{6}=\alpha_{7}=0$

$\mathrm{H}_{1}: \alpha_{1} \neq \alpha_{2} \neq \alpha_{3} \neq \alpha_{4} \neq \alpha_{5} \neq \alpha_{6} \neq \alpha_{7} \neq 0$

Keterangan:

$\left[\mathrm{Y}_{2}=\right.$ PDRB Sektor Kehutanan (juta rupiah/ kabupaten, kota)

$[\mathrm{HN}]_{\mathrm{it}} \quad=$ Hutan Negara (ha)

$[\mathrm{HR}]_{\mathrm{it}} \quad=$ Hutan Rakyat (ha)

$[\mathrm{PTN}]_{\mathrm{it}} \quad=$ Pertanian Lahan Kering (ha)

$[\mathrm{SWH}]_{\mathrm{it}} \quad=$ Sawah (ha)

$[\mathrm{LTEB}]_{\mathrm{it}} \quad=$ Lahan Terbangun (ha)

$[\mathrm{KPD}]_{\mathrm{it}} \quad=$ Kepadatan Penduduk (jiwa $/ \mathrm{km}^{2}$ )

$[\mathrm{AL}]_{\mathrm{it}} \quad=$ Areal Lain (ha)

$e_{i} \quad=$ error model

$\alpha_{0}, \alpha_{1}, \ldots \alpha_{7} \quad=$ Parameter Model

\section{PDRB Sektor Industri}

$[\mathrm{Y}]_{3}=\gamma_{0}+\gamma_{1}[\mathrm{HN}]_{\mathrm{it}}+\gamma_{2}[\mathrm{HR}]_{\mathrm{it}}+\gamma_{3}[\mathrm{PTN}]_{\mathrm{it}}+\gamma_{4}[\mathrm{SWH}]_{\mathrm{it}}+\gamma_{5}[\mathrm{PKB}]_{\mathrm{it}}+\gamma_{6}[\mathrm{KPD}]_{\mathrm{it}}+e_{i}$

\section{Hipotesis}

$\mathrm{H}_{0}: \gamma_{1}=\gamma_{2}=\gamma_{3}=\gamma_{4}=\gamma_{5}=\gamma_{6}=0$

$H_{1}: \gamma_{1} \neq \gamma_{2} \neq \gamma_{3} \neq \gamma_{4} \neq \gamma_{5} \neq \gamma_{6} \neq 0$ 
Keterangan:

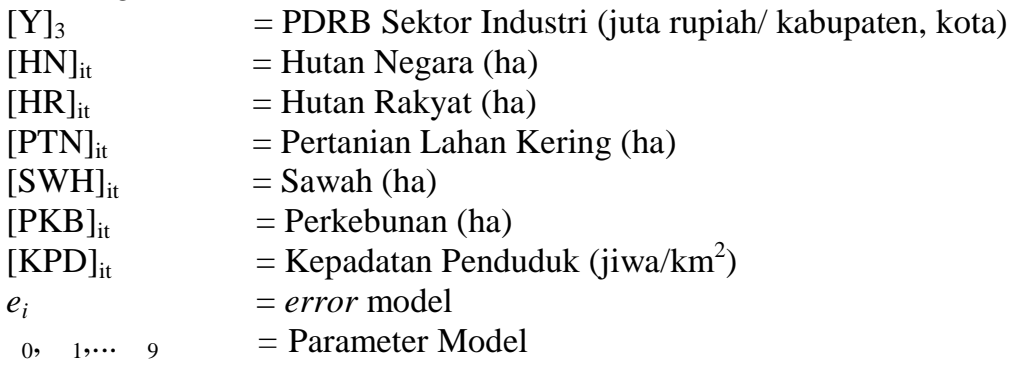

Optimasi parameter model dengan menggunakan software statistik. Signifikansi pengaruh variabel independen terhadap variabel dependen dalam model tersebut akan digunakan uji T. Sedangkan uji masing-masing variabel independen terhadap variabel dependen akan digunakan uji F pada taraf nyata $10 \%$.

\section{HASIL DAN PEMBAHASAN}

\section{A. Dinamika Perubahan Tutupan Hutan dan Lahan}

Tabel 1. Hasil interpretasi citra landsat tentang perubahan tutupan hutan dan lahan Provinsi Lampung tahun 2002, 2009 dan 2014.

\begin{tabular}{llllllll}
\hline & {$[\mathbf{H N}]$} & {$[\mathbf{H R}]$} & {$[\mathbf{P T N}]$} & {$[\mathbf{S W H}]$} & {$[\mathbf{P K B}]$} & {$[\mathbf{L T E B}]$} & [AL] \\
\hline Minimum & 0.00 & 0.00 & 1.01 & 0.00 & 0.00 & 1.79 & 0.18 \\
Maximum & 51.85 & 41.05 & 49.16 & 39.74 & 52.06 & 46.45 & 28.46 \\
Rataan & 12.26 & 12.18 & 17.96 & 14.35 & 17.58 & 14.48 & 9.23 \\
St Deviasi & 14.60 & 8.69 & 11.85 & 11.10 & 16.63 & 12.13 & 8.47 \\
\hline
\end{tabular}

Sumber: Data primer hasil interpretasi citra Landsat

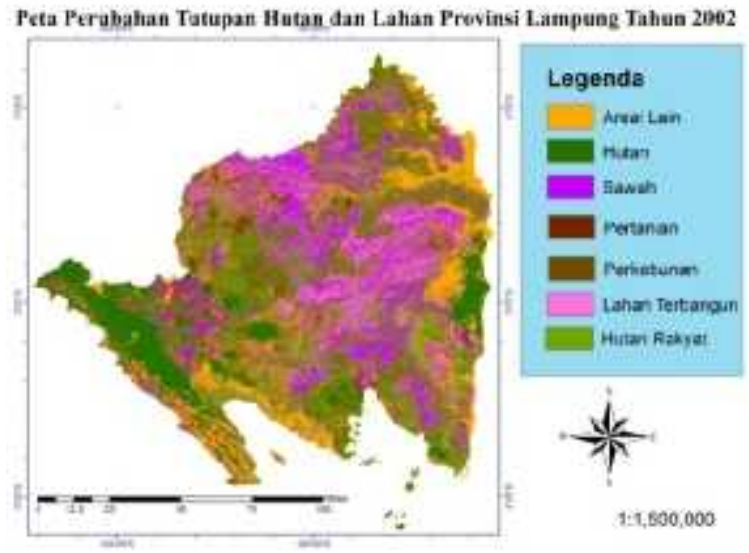

(A) 


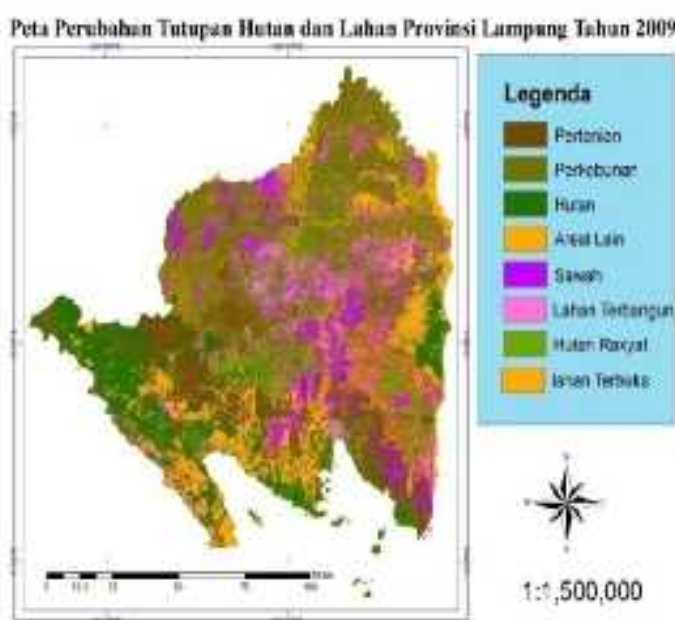

(B)

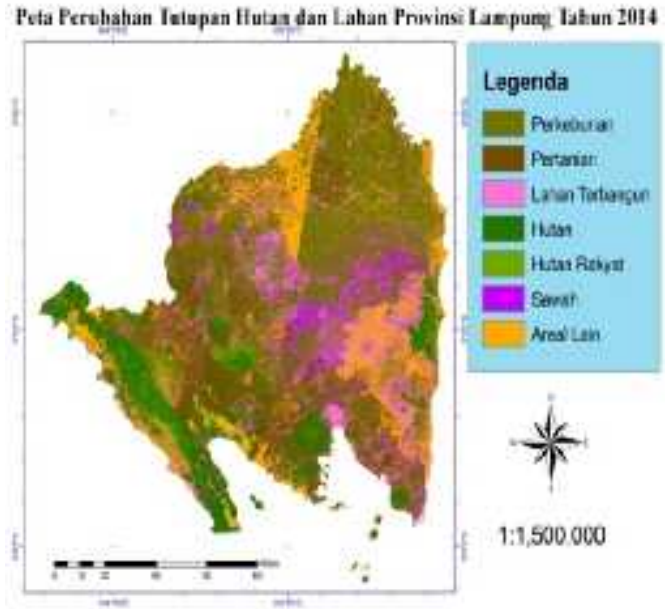

(C)

Gambar 1. Perubahan tutupan hutan dan lahan di Provinsi Lampung (A) tahun 2002, (B) tahun 2009, dan (C) tahun 2014.

\section{B. Hubungan PDRB Sektor Pertanian dengan Luas Tutupan Hutan dan Lahan}

\section{a. PDRB Sektor Pertanian di Provinsi Lampung}

Tabel 2. PDRB Sektor pertanian atas harga konstan menurut lapangan usaha tahun 2002, 2009 dan 2014 .

\begin{tabular}{ccccc}
\hline Tahun & Rata-rata & Minimum & Maximum & St Deviasi \\
\hline 2002 & 38.82 & 1.82 & 62.89 & 17.58 \\
2009 & 36.16 & 1.41 & 55.44 & 16.63 \\
2013 & 27.29 & 2.00 & 43.58 & 13.72 \\
\hline 3 Tahun & 34.09 & 1.74 & 53.97 & 15.98 \\
\hline
\end{tabular}

Sumber: Badan Pusat Statistik Provinsi Lampung

Rata-rata PDRB sektor pertanian pada kurun waktu 2002, 2009 serta 2013 di Provinsi Lampung menyumbangkan 34.09\% dari seluruh sektor di Provinsi Lampung dengan rata-rata nilai persebaran (St Dev) sebesar 15.98\%. PDRB di sektor pertanian di Provinsi Lampung terus mengalami penurunan setiap tahunnya, hal ini dikarenakan adanya konversi lahan pertanian menjadi lahan terbangun. PDRB pertanian tertinggi di Provinsi Lampung yaitu pada tahun 2002 dengan rata-rata 38.82 dari seluruh kabupaten kota di Provinsi Lampung.

\section{b. Uji-TRegresi Linier PDRB di Sektor Pertanian dengan Variabel Dependen}

Tabel 3. Hasil optimasi parameter model pengaruh perubahan tutupan hutan dan lahan terhadap PDRB di sektor pertanian (juta rupiah/ kabupaten, kota).

\begin{tabular}{llcccc}
\hline \multicolumn{1}{c}{ Simbol } & \multicolumn{1}{c}{ Predictor } & Coef & SE Coef & T & P \\
\hline Constant & & 37.345 & 5.370 & 6.95 & 0.000 \\
{$[\mathrm{HN}]$} & Hutan Negara & 2.156 & 2.148 & 1.00 & 0.326 \\
{$[\mathrm{HR}]$} & Hutan Rakyat & 11.055 & 5.643 & 1.96 & 0.062 \\
{$[\mathrm{LTEB}]$} & Lahan terbangun & -9.189 & 6.513 & -1.41 & 0.172 \\
{$[\mathrm{SWH}]$} & Sawah & 7.982 & 4.393 & 1.82 & 0.082 \\
{$[\mathrm{KPD}]$} & Kepadatan Penduduk & -8.676 & 1.638 & -5.30 & 0.000 \\
{$[\mathrm{AL}]$} & Areal Lain & -4.938 & 3.691 & -1.34 & 0.194 \\
\hline $\mathrm{S}=7.14437$ & \multicolumn{2}{c}{ R-Sq=84.7\% } & R-Sq(adj)=80.8\% & & $\mathrm{P}_{\text {value }}=0.000$ \\
\hline
\end{tabular}

Sumber : Hasil penelitian (2016) 
Melalui perhitungan regresi yang telah dilakukan dapat diketahui bahwa koefisien determinasi yang disesuaikan $\left(\mathrm{R}_{a d j}\right)$ adalah sebesar $80.8 \%$. Nilai determinasi yang dapat disesuaikan tersebut artinya variabel $\mathrm{X}$ dapat menjelaskan nilai PDRB sektor pertanian sebesar $80.8 \%$ dan sisanya sebesar $19.2 \%$ dijelaskan oleh variabel lain yang tidak dimasukkan dalam model estimasi. Hasil regresi menunjukkan bahwa luas hutan rakyat, luas sawah dan kepadatan penduduk berpengaruh nyata terhadap PDRB di sektor pertanian, sedangkan luas hutan negara, luas lahan terbangun dan areal lain tidak berpengaruh nyata terhadap PDRB di sektor pertanian. Berikut adalah hubungan hasil regresi yang berpengaruh nyata terhadap PDRB di sektor pertanian.

\section{Hubungan luas hutan rakyat dengan PDRB sektor pertanian}

Nilai koefisien luas hutan rakyat sebesar 11.055 menunjukkan bahwa terdapat hubungan positif antara luas hutan rakyat dengan PDRB di sektor pertanian. Dengan demikian, setiap kenaikkan satu hektar luas hutan rakyat akan meningkatkan Rp. 11.055.000,- PDRB sektor pertanian. Masyarakat di Indonesia menanam lahan kering dengan pola campuran atau tumpang sari dengan mengkombinasikan tanaman keras/kayu-kayuan dengan tanaman pangan(umbiumbian), buah-buahan dan empon-empon, dengan demikian masyarakat dapat memperoleh keuntungan ganda dari hasil kayu dan tanaman pangan tersebut. Pola percampuran berbagai jenis tanaman dalam satu lahan (mix plantation) memiliki nilai lebih bagi petani (Suryaningsih, 2012).

\section{Hubungan Luas Sawah dengan PDRB Sektor Pertanian}

Sektor pertanian berperan dalam pembangunan terutama pada negara yang sedang berkembang (Manehat, 2014). Sawah merupakan salah satu sub pertanian yang menyediakan bahan makanan pokok (Azwir, 2009). Berdasarkan hasil regresi membuktikan bahwa besarnya p-value adalah 0.082 , hal tersebut membuktikan bahwa luas sawah berpengaruh nyata terhadap PDRB di sektor Pertanian. Nilai koefisien luas sawah sebesar 7.982, hal tersebut menunjukkan terdapat hubungan positif antara luas sawah dengan PDRB di sektor pertanian. Hasil regresi dengan demikian menjelaskan bahwa setiap satu hektar sawah dapat meningkatkan Rp. 7.982.000,- PDRB sektor pertanian.

\section{Hubungan Kepadatan Penduduk dengan PDRB Sektor Pertanian}

Kepadatan penduduk memiliki hubungan yang erat dengan luas lahan pertanian karena peningkatan jumlah penduduk mengakibatkan berkurangnya luas lahan pertanian yang disebabkan adanya alih fungsi lahan pertanian ke non pertanian (Tulenan, 2014). Berdasarkan hasi regresi bahwa nilai $p$-value yaitu 0.000 , maka kepadatan penduduk berpengaruh nyata terhadap PDRB di sektor pertanian. Nilai koefisien kepadatan penduduk yaitu sebesar -8.676, hal tersebut menunjukkan bahwa terdapat hubungan negative antara kepadatan penduduk dengan PDRB di sektor pertanian. Dengan demikian bahwa setiap kepadatan penduduk per $\mathrm{km}^{2}$ akan menurunkan Rp. 8.676.000,- PDRB di sektor pertanian.

\section{B. Hubungan PDRB Sektor Kehutanan dengan Luas Tutupan Hutan dan Lahan}

\section{a. PDRB Sektor Kehutanan di Provinsi Lampung}


Tabel 4. PDRB sektor kehutanan atas harga konstan menurut lapangan usaha tahun 2002, 2009 dan 2014 (dalam \%).

\begin{tabular}{crrrc}
\hline Tahun & Rata-Rata & Minimum & Maximum & St Deviasi \\
\hline 2002 & 0.43 & 0.00 & 2.85 & 0.87 \\
2009 & 0.87 & 0.00 & 3.62 & 1.38 \\
2014 & 0.74 & 0.00 & 4.22 & 1.29 \\
\hline 3 Tahun & 0.68 & 0.00 & 3.56 & 1.18 \\
\hline
\end{tabular}

Sumber: Badan Pusat Statistik Provinsi Lampung

Rata-rata PDRB di sektor kehutanan di Provinsi Lampung pada tahun 2002, 2009 dan 2014 yaitu sebesar $0.68 \%$ dengan nilai persebaran (St Dev) yaitu sebesar 1.18\%. PDRB sektor kehutanan yang tertinggi terjadi pada tahun 2009 yaitu rata-rata sebesar $0.87 \%$.

\section{b. Uji-T Regresi Linier PDRB di Sektor Kehutanan dengan Variabel Dependen}

Tabel 5. Hasil optimasi parameter model pengaruh perubahan tutupan hutan dan lahan terhadap PDRB di sektor kehutanan (juta rupiah/ kabupaten, kota).

\begin{tabular}{|c|c|c|c|c|c|}
\hline Simbol & Predictor & Coef & SE Coef & $\mathrm{T}$ & $\mathrm{P}$ \\
\hline Constant & & 0.5832 & 0.6799 & 0.86 & 0.400 \\
\hline$[\mathrm{HN}]$ & Hutan Negara & 1.1600 & 0.242 & 4.79 & 0.000 \\
\hline [HR] & Hutan Rakyat & 0.8340 & 0.624 & 1.34 & 0.195 \\
\hline$[\mathrm{PTN}]$ & $\begin{array}{l}\text { Pertanian Lahan } \\
\text { Kering }\end{array}$ & -0.3970 & 0.469 & -0.85 & 0.406 \\
\hline$[\mathrm{SWH}]$ & Sawah & -0.2140 & 0.479 & -0.45 & 0.660 \\
\hline [LTEB] & Lahan Terbangun & 0.1890 & 0.715 & 0.26 & 0.794 \\
\hline [KPD] & $\begin{array}{l}\text { Kepadatan } \\
\text { Penduduk }\end{array}$ & -1.1679 & 1.982 & -0.85 & 0.406 \\
\hline [AL] & Areal Lain & -0.8030 & 0.0407 & -1.97 & 0.061 \\
\hline$S=0.778675$ & $\mathrm{R}-\mathrm{Sq}=66.8 \%$ & $\mathrm{R}-\mathrm{Sq}(\operatorname{adj})=56.2 \%$ & $\mathrm{P}_{\text {Value }}$ & & \\
\hline
\end{tabular}

Sumber : Hasil penelitian (2016)

Hasil perhitungan regresi menunjukkan bahwa koefisien determinasi yang disesuaikan $\left(\mathrm{R}_{a d j}\right)$ adalah sebesar $56.2 \%$. Nilai koefisien determinasi yang disesuaikan tersebut menjelaskan bahwa variabel X dapat menjelaskan nilai PDRB di sektor kehutanan sebesar $56.2 \%$ dan sisanya $43.8 \%$ dijelaskan oleh variabel lain yang tidak dijelaskan dalam model estimasi. Hasil regresi menunjukkan bahwa luas hutan negara dan luas areal lain berepengaruh nyata terhadap PDRB di sektor kehutanan, sedangkan luas hutan rakyat, luas pertanian lahan kering, luas sawah, luas lahan terbangun dan kepadatan penduduk tidak berpengaruh nyata terhadap PDRB di sektor kehutanan. Berikut adalah hubungan luas lahan yang berpengaruh nyata terhadap PDRB sektor kehutanan.

\section{Hubungan Luas Hutan Negara dengan PDRB Sektor Kehutanan}

Hutan merupakan salah satu sumberdaya alam yang memiliki nilai ekonomi, ekologi dan sosial yang tinggi. Sebagai salah satu sumberdaya alam yang dapat dimanfaatkan untuk memenuhi berbagai kebutuhan manusia, manfaat hutan dapat dapat dibedakan menjadi dua yaitu yaitu tangible (langsung/nyata) dan intangible (tidak langsung/tidak nyata) (Latifah, 2004 dalam Susilawati, 2008). Berdasarkan hasil regresi nilai $p$ - value yaitu sebesar 0.000 yang menunjukkan bahwa hutan negara berpengaruh nyata terhadap sektor kehutanan. Nilai koefisien luas hutan negara sebesar 1.160, hal tersebut menunjukkan terdapat hubungan positif antara luas hutan 
negara dengan PDRB di sektor kehutanan. Hasil regresi dengan demikian menjelaskan bahwa setiap satu hektar hutan negara dapat meningkatkan Rp. 1.160.000,- PDRB sektor kehutanan.

\section{Hubungan Luas Areal Lain dengan PDRB Sektor Kehutanan}

Areal lain yang dimaksudkan disini adalah luas lahan mangrove, luas rawa, luas tambak, luas areal terbuka, luas badan air, luas awan dan bayangan awan. Luas lahan areal lain rata-rata adalah luas perairan yang didominasi oleh lahan tambak yang secara otomatis apabila lahan perairan lebih banyak maka pendapatan di subsektor perikanan pun akan meningkat sehingga akan mengurangi pendapatan di subsektor lainnya termasuk subsektor kehutanan. Dalam penelitian Parwali tahun 2006 dinyatakan bahwa permasalahn pesisir menjadi pelik dengan adanya konflik kepentingan antara konservasi pembangunan ekonomi dengan konversi lahan menjadi lahan pertanian, industri, pemukiman dan peruntukkan lainnya. Berdasarkan hasil regresi nilai $p$ - value yaitu sebesar 0.061, hal tersebut menunjukkan bahwa luas areal lain berpengaruh nyata terhadap PDRB sektor kehutanan. Nilai koefisien luas areal lain sebesar -0.803, hal tersebut menunjukkan terdapat hubungan negative antara luas areal lain dengan PDRB di sektor kehutanan. Hasil regresi tersebut dengan demikian menjelaskan bahwa setiap satu hektar areal lain dapat menurunkan Rp.803.000,- PDRB sektor kehutanan.

\section{Hubungan PDRB Sektor Industri dengan Luas Tutupan Hutan dan Lahan}

\section{a. PDRB Sektor Industri di Provinsi Lampung}

Tabel 6. PDRB Sektor Industri Atas Harga Konstan Menurut Lapangan Usaha Tahun 2002, 2009 dan 2014.

\begin{tabular}{crrrr}
\hline Tahun & Rata-rata & Minimum & Maximum & St Deviasi \\
\hline 2002 & 8.19 & 1.29 & 22.33 & 6.74 \\
2009 & 10.90 & 3.29 & 19.35 & 5.76 \\
2014 & 15.52 & 4.60 & 23.70 & 6.84 \\
\hline Rata-rata & 11.53 & 3.06 & 21.79 & 6.45 \\
\hline
\end{tabular}

Sumber: Badan Pusat Statistik Provinsi Lampung

Rata-rata kontribusi PDRB sektor Industri pada tahun 2002, 2009 dan 2014 di Provinsi Lampung yaitu sebesar $11.53 \%$ dari seluruh sektor yang terdapat di Provinsi Lampung dengan nilai persebaran (St Dev) yaitu 6.45 .

\section{B. Uji-TRegresi Linier PDRB di Sektor Industri dengan Variabel Dependen}

Tabel 7. Hasil optimasi parameter model pengaruh perubahan tutupan hutan dan lahan terhadap PDRB di sektor industri (juta rupiah/ kabupaten, kota).

\begin{tabular}{llrrrr}
\hline Simbol & Predictor & Coef & SE Coef & T & P \\
\hline Constant & & 5.892 & 2.893 & 2.04 & 0.053 \\
{$[\mathrm{HN}]$} & Hutan Negara & -1.741 & 1.553 & -1.12 & 0.274 \\
{$[\mathrm{HR}]$} & Hutan Rakyat & -7.434 & 4.016 & -1.85 & 0.077 \\
{$[\mathrm{PTN}]$} & Pertanian Lahan Kering & 4.433 & 2.652 & 1.67 & 0.108 \\
{$[\mathrm{SWH}]$} & Sawah & 3.157 & 2.701 & 1.17 & 0.255 \\
{$[\mathrm{PKB}]$} & Perkebunan & 5.471 & 1.134 & 4.83 & 0.000 \\
\hline $\mathrm{S}=4.44332$ & \multicolumn{2}{c}{$\mathrm{R}-\mathrm{Sq}=67.6 \%$} & $\mathrm{R}-\mathrm{Sq}(\mathrm{adj})=59.2 \%$ & $\mathrm{P}_{\text {Value }}=0.00$ & \\
\hline
\end{tabular}

Sumber : Hasil penelitian (2016) 
Hasil perhitungan regresi menunjukkan bahwa koefisien determinasi yang disesuaikan $\left(\mathrm{R}_{a d j}\right)$ adalah sebesar 59.2\%. Nilai koefisien determinasi yang disesuaikan tersebut artinya variabel X dapat menjelaskan nilai PDRB di sektor Industri sebesar 59,2\% dan sisanya sebesar $40.8 \%$ dijelaskan oleh variabel lain yang tidak dimasukkan dalam model estimasi. Berdasarkan hasil regresi, luas hutan rakyat dan luas perkebunan berpengaruh nyata terhadap PDRB di sektor industri, sedangkan luas hutan negara, luas pertanian lahan kering dan luas sawah tidak berpengaruh nyata terhadap PDRB sektor industri. Berikut hubungan luas lahan yang berpengaruh nyata terhadap PDRB sektor industri.

\section{Hubungan Luas Hutan Rakyat dengan PDRB Sektor Industri}

Berdasarkan hasi regresi di dapatkan p-value sebesar 0.077 yang membuktikan bahwa luas hutan rakyat berpengaruh nyata terhadap pendapatan di sektor industri. Nilai koefisien hutan rakyat sebesar -7.434 , hal tersebut menunjukkan terdapat hubungan negative antara luas hutan rakyat dengan PDRB di sektor industri. Hasil regresi tersebut dengan demikian menjelaskan bahwa setiap satu hektar hutan rakyat dapat menurunkan Rp. 7.434.00,- PDRB sektor industri. Hutan rakyat di Lampung menerapkan sistem agroforestri, dimana pemanfaatan untuk hasil dari hutan rakyat tersebut hanya dijual dalam bentuk bahan mentah tanpa adanya pengolahan.

\section{Hubungan Luas Perkebunan dengan PDRB Sektor Industri}

Berdasarkan hasil regresi hasil $p$ - value dari luas perkebunan yaitu 0.00 , hal tersebut membuktikan bahwa luas perkebunan berpengaruh nyata terhadap sektor industri. Nilai koefisien perkebunan sebesar 5.471, hal tersebut menunjukkan terdapat hubungan positif antara luas perkebunan dengan PDRB di sektor industri. Hasil regresi tersebut dengan demikian menjelaskan bahwa setiap satu hektar luas perkebunan dapat meningkatkan Rp. 5.471.00,- PDRB sektor industri. Menurut data BPS tahun 2014 penyumbang terbesar dari sektor industri adalah subsektor industri pengolahan bahan makanan dan minuman. Sub sektor ini sangat bergantung dari sektor pertanian termasuk perkebunan dalam menghasilkan bahan baku yang dibutuhkan suatu perusahaan atau pun unit usaha (Manik, 2013).

\section{KESIMPULAN}

Hasil penelitian menunjukkan bahwa terdapat hubungan yang berarti antara perubahan tutupan hutan rakyat yaitu sebesar Rp.11.055.000,- /ha/thn $(\mathrm{p}=0.062)$, sawah Rp.7.982.000,/ha/thn $(\mathrm{p}=0.082)$, serta kepadatan penduduk Rp. -8.676.000,-/ha/thn $(\mathrm{p}=0.000)$ terhadap PDRB di sektor pertanian. PDRB di sektor kehutanan dipengaruhi secara nyata oleh tutupan hutan negara sebesar Rp.1.160.000,-/ha/thn $(\mathrm{p}=0.00)$ dan areal lain Rp.-803.000,-/ha/thn $(\mathrm{p}=$ 0.061). PDRB di sektor industri secara nyata oleh tutupan hutan rakyat Rp.-7.434.000,-/ha/thn $(\mathrm{p}=0.077)$, dan perkebunan Rp.5.471.000/ha/thn $(\mathrm{p}=0.00)$. 


\section{DAFTAR PUSTAKA}

Azwir, dan Ridwan. 2009. Peningkatan produktivitas padi sawah dengan perbaikan teknologi budidaya. Jurnal Agrosia. 12(2):212-218.

Badan Pusat Statistik 2010-2014. Produk Domestik Regional Bruto Provinsi lampung Menurut Lapangan Usaha. Buku. BPS Provinsi Lampung. Lampung. 77 p.

— 2000. Tinjauan Ekonomi Regional Daerah Otonom di Provinsi Lampung 2000. Buku. BPS Provinsi Lampung. Lampung. 114 p.

- 2010. Tinjauan Ekonomi Regional Daerah Otonom di Provinsi Lampung 2009. Buku. BPS Provinsi Lampung. Lampung. 124 p.

2015. Tinjauan Ekonomi Regional Daerah Otonom di Provinsi Lampung 2014. Buku. BPS Provinsi Lampung. Lampung. 124 p.

Bapedda. 2013. Statistik Perekonomian Lampung. Buku. Bapedda Provinsi lampung. Lampung. $321 \mathrm{p}$.

Manehat, M.S, Marthen, R.P. dan Prijo, S. 2014. Potensi lahan dan tenaga kerja terhadap pemanfaatan air di daerah irigasi Kecamatan Kupang Tengah Kabupaten Kupang-NTT. Jurnal Ilmu Lingkungan. 12:42-52.

Manik, Y.H., Hanung, I. dan Helvi, Y. 2013. Analisis basis ekonomi subsektor industri pengolahan hasil pertanian dan kehutanan di Kota Bandar Lampung. Jurnal JIIA. 1(2):162-168.

Parwali, E., Bambang, T., ila, C., Talik, K., Sri, H. dan Katih., D. 2006. Analisis hubungan penutup/penggunaan lahan dengan total suspended matter (TSM) kawasan perairan Segara anakan menggunakan data inderaja. Jurnal Penginderaan Jauh. 3(1):87—98.

Rohmadiani, L.D. 2011. Dampak konversi lahan pertanian terhadap kondisi sosial ekonomi petani. Jurnal Teknik Waktu. 9(2):1412-1867.

Suryaningsih, W.H., Hartuti, P. dan Muniffatul, I. 2012. Persepsi masyarakat dalam pelestarian hutan rakyat di Desa Karangrejo Kecamatan Loano Kabupaten Purworejo. Prosiding Seminar Nasional Sumberdaya Alam dan Lingkungan, Semarang 11 September.

Surni. 2015. Dinamika perubahan penggunaan lahan, penutupan lahan terhadap hilangnya biodiversitas di DAS Tallo, Sulawesi Selatan. Prosiding Seminar Masyarakat Biodiversitas Indonesia. 1(5):1050-1055.

Susilawati, D. 2008. Analisis dampak dan faktor yang mempengaruhi perambahan hutan (Studi Kasus Desa Bulu Hadik, Kecamatan Teluk Datar, Kabupaten, Simeuleu, NAD. Skripsi. Universitas Sumatera Utara. Medan. 84 p.

Tulenan, Y.F.A. 2014. Perkembangan jumlah penduduk dan luas lahan pertanian di Kabupaten Minahasa Selatan. Artikel. http://download.portalgaruda. org/article $=141354 \&$ val=1027 \&title=PERKEMBANGAN\%20JUMLAH $\% 20$ PENDUDU K\%20DAN\%20LUAS\%20LAHAN\%PERTANIAN\%20DI\%20KABUPATEN\%20MIN AHASA\%20SELATAN. Diakses pada 29 Maret 2016. 